\title{
Erratum to: Some Tribological Influences on the Electrode-Worksheet Interface During Resistance Spot Welding of Aluminum Alloys
}

M. Rashid, John B. Medley, and Norman Y. Zhou

\section{Erratum to: J. of Materi Eng and Perform \\ DOI 10.1007/s11665-010-9696-z}

Please note that the names of Dr. John B. Medley and Dr. Norman Y. Zhou were inadvertently omitted from the author line for this article. The proper list of Authors is mentioned here.

The online version of the original article can be found under doi:10.1007/s11665-010-9696-z.

M. Rashid, CANMET, Materials Technology Laboratory, Natural Resources Canada, 568 Booth Street, Ottawa, ON K1A 0G1, Canada and Department of Mechanical \& Mechatronics Engineering, University of Waterloo, 200 University Avenue West, Waterloo, ON N2L 3G1, Canada; and John B. Medley and NormanY. Zhou, Department of Mechanical \& Mechatronics Engineering, University of Waterloo, 200 University Avenue West, Waterloo, ON N2L 3G1, Canada. Contact e-mails: murashid@nrcan.gc.ca,jmedley@mecheng1. uwaterloo.ca, and nzhou@mecheng1.uwaterloo.ca. 